*2nd Pulmonary Medicine Dept, Attikon University Hospital, 2nd Dept of Critical Care Medicine, Attikon University Hospital, Athens Medical School, National and Kapodistrian University of Athens, and ${ }^{\#} 1$ st Pulmonary Medicine Dept, Sotiria Chest Diseases Hospital, Athens Medical School, National and Kapodistrian University of Athens, Athens, Greece. ${ }^{+}$These authors contributed equally.

Correspondence: S.A. Papiris, 2nd Pulmonary Medicine Dept, Attikon University Hospital, 1 Rimini Street, 12462 Haidari, Greece. E-mail: papiris@otenet.gr

Statement of Interest: None declared.

\section{REFERENCES}

1 Raghu G, Collard HR, Egan JJ, et al. An Official ATS/ERS/JRS/ ALAT statement: idiopathic pulmonary fibrosis: evidence-based guidelines for diagnosis and management. Am J Respir Crit Care Med 2011; 183: 788-824.

$2 \mathrm{du}$ Bois RM. Strategies for treating idiopathic pulmonary fibrosis. Nat Rev Drug Discov 2010; 9: 129-140.

3 Papiris SA, Manali ED, Kolilekas L, et al. Clinical review: idiopathic pulmonary fibrosis acute exacerbations - unravelling Ariadne's thread. Crit Care 2010; 14: 246.
4 National Heart, Lung, and Blood Institute. NIH News. Commonly used three-drug regimen for idiopathic pulmonary fibrosis found harmful. October 21, 2011. www.nih.gov/news/health/oct2011/ nhlbi-21.htm Date last accessed: January 22, 2012.

5 Azuma A, Nukiwa T, Tsuboi E, et al. Double-blind, placebocontrolled trial of pirfenidone in patients with idiopathic pulmonary fibrosis. Am J Respir Crit Care Med 2005; 171: 1040-1047.

6 Taniguchi H, Ebina M, Kondoh Y, et al. Pirfenidone in idiopathic pulmonary fibrosis. Eur Respir J 2010; 35: 821-829.

7 Noble PW, Albera C, Bradford WZ, et al. Pirfenidone in patients with idiopathic pulmonary fibrosis (CAPACITY): two randomised trials. Lancet 2011; 377: 1760-1769.

8 Collard HR, King TE Jr, Bartelson BB, et al. Changes in clinical and physiologic variables predict survival in idiopathic pulmonary fibrosis. Am J Respir Crit Care Med 2003; 168: 538-542.

9 du Bois RM, Weycker D, Albera C, et al. Forced vital capacity in patients with idiopathic pulmonary fibrosis: test properties and minimal clinically important difference. Am J Respir Crit Care Med 2011; 184: 1382-1389.

10 Guyatt GH, Osoba D, Wu AW, et al. Methods to explain the clinical significance of health status measures. Mayo Clin Proc 2002; 77: 371-383.

11 Man-Son-Hing M, Laupacis A, O'Rourke K, et al. Determination of the clinical importance of study results. J Gen Intern Med 2002; 17: $469-476$.

\title{
Primary pulmonary extranodal natural killer/T-cell lymphoma: nasal type with multiple nodules
}

\section{To the Editors:}

Primary pulmonary lymphoma (PPL) is an uncommon disease representing only $3-4 \%$ of extranodal non-Hodgkin's lymphoma (NHL), and $<1 \%$ of NHL [1]. The true incidence of PPL other than NHL is unknown, while primary pulmonary T-cell lymphoma is extremely rare. Natural killer (NK)/T-cell lymphoma usually shows an extranodal presentation. Nasal NK/Tcell lymphomas occur in the nose and the upper aerodigestive tract. Extranasal NK/T-cell lymphomas represent the counterpart of nasal NK/T-cell lymphomas and can involve every other part of the body. Primary sites of involvement are mainly the skin, soft tissue, gastrointestinal tract and testis [2]. Although some cases of primary pulmonary T-cell lymphoma have been reported, there are only two reports written in English to date $[3,4]$. Here, we describe a case of primary pulmonary NK/T-cell lymphoma with multiple nodules in both lung fields.

The patient was a 50-yr-old Japanese male with an abnormal shadow on chest radiography in a health examination (fig. 1a). He was an office worker with no history of dust inhalation or asbestos exposure and was a current smoker (50 pack-yrs). He had a history of hypertension and gallstones. He had a high fever of over $39^{\circ} \mathrm{C}$ for 10 days before the health examination, and had appetite loss and general fatigue. A chest computed tomography (CT) on admission revealed multiple nodules, measuring a maximum of $40 \mathrm{~mm}$ in size, were in both lung fields (fig. 1b-d). Administration of broad-spectrum antibiotics did not resolve his symptoms. Bronchoscopic examination and CT-guided needle biopsy did not give a definite diagnosis. Laboratory data showed elevation of lactate dehydrogenase, transaminases, hepatobiliary enzymes and an inflammatory reaction without cytopenia. Two sets of blood cultures were both negative and no tumour markers were elevated. Anti-neutrophil cytoplasmic antibodies were negative and soluble interleukin (IL)-2 receptor was elevated to 5,060 $\mathrm{U} \cdot \mathrm{mL}^{-1}$. Although we first planned a surgical biopsy to make a definitive diagnosis, it was not performed due to the rapid deterioration in his performance status. The final needle aspiration showed lymphocytes of various morphologies invading the blood vessels.

At this point, we suspected pulmonary lymphoma, such as lymphomatoid granulomatosis. The Otolaryngologists investigation of the upper respiratory tracts showed no specific findings. Lung nodules increased and grew larger, and hypoxia progressed. His clinical condition deteriorated so rapidly that we had to start treatment without a definitive diagnosis. He was treated with methylprednisolone (mPSL) pulse therapy (1,000 mg per day for 3 days) twice followed by cyclophosphamide pulse therapy (500 mg per day) as a salvage therapy. Progressive hypoxia was temporarily improved; however, his respiratory condition immediately worsened. Direct haemoperfusion using a polymyxin B immobilised fibre column was also performed; 

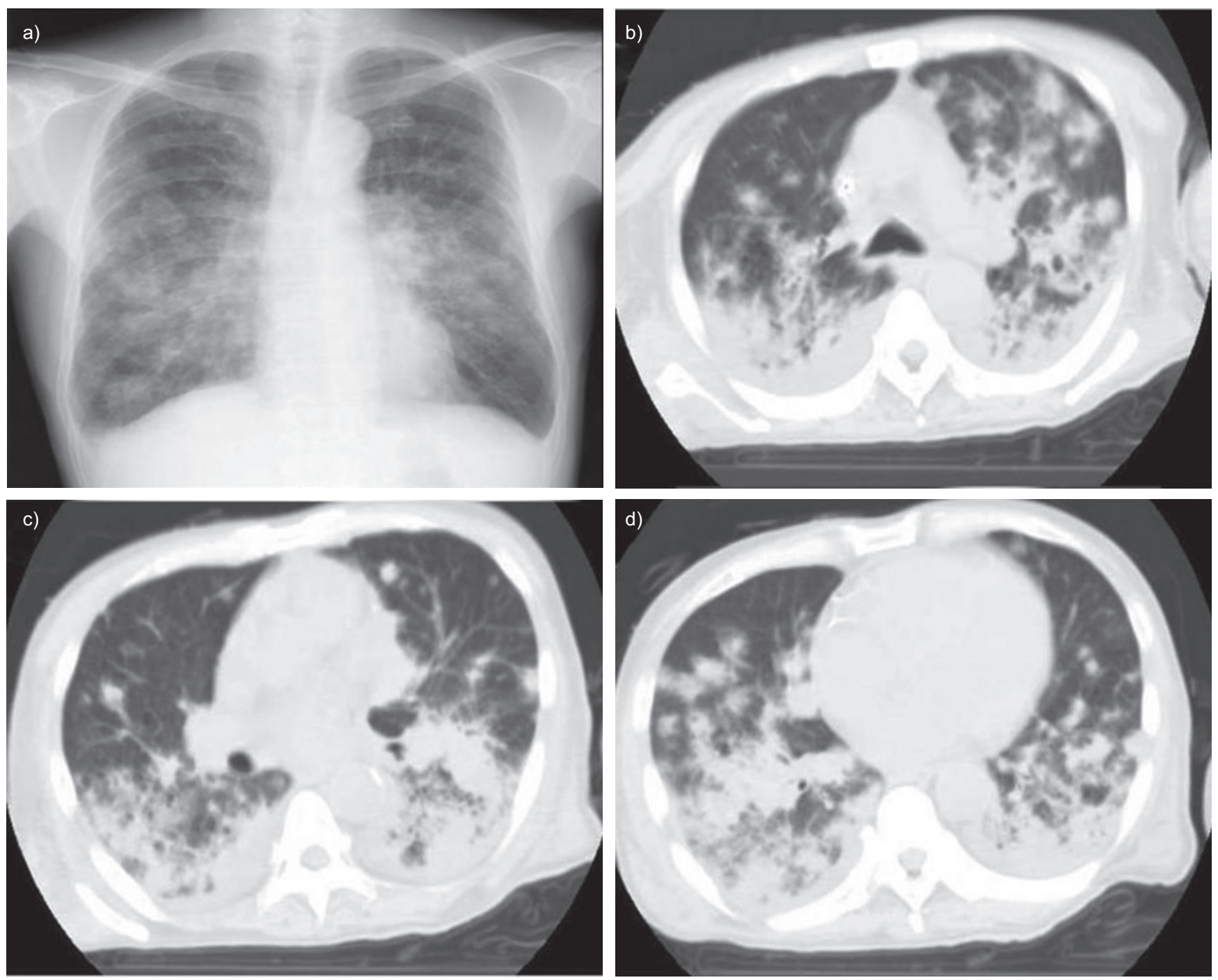

FIGURE 1. a) Chest radiograph, and b) upper, c) middle and d) lower computed tomography images on admission showing bilateral nodules in both lung fields.

however, it improved the condition only temporarily. At 10 days after the second mPSL pulse therapy, when continuous haemodiafiltration was started for progressive renal insufficiency, he developed marked hepatosplenomegaly. His clinical condition continued to deteriorate in spite of the intensive treatment. His respiratory condition worsened progressively and he died of multiple organ failure on the 29th day after admission.

The post mortem examination showed multiple whitish nodular lesions in both lungs. These nodular lesions were also seen on the cut surface of the heart. Slight lymphadenopathy was seen in the mediastinum, paratracheal, bifurcation and bilateral hilar regions. The spleen was swollen and fragile, and the liver was markedly enlarged.

The microscopic examination showed that medium to large sized atypical lymphoid cells proliferated in both lungs, the myocardium, the spleen, the portal areas, both adrenal glands, the interstitium of both kidneys, the marrow of the examined bones (sternum, vertebrae and rib), the lymph nodes in the mediastinum, and the paratracheal, bifurcation and bilateral hilar regions, but not in the entire gastrointestinal tract. The cells stained positively for cytoplasmic CD3, CD56 and Epstein-Barr virus (EBV)-encoded small RNA (fig. 2b-d), but negatively for CD20 and CD79 (B-cell markers). As CD3 and CD56 are T- and NK-cell markers, respectively, the immunocytochemistry showed that these atypical lymphoid cells were of T- and NK-cell lineages. Based on the neoplastic morphology and the immunohistochemical examination of the atypical lymphocytes, the pathological diagnosis was extranodal NK/T-cell lymphoma (nasal type).

According to the World Health Organization 2008 classification, NK-cell tumours are classified into two types: 1) extranodal NK/T-cell lymphoma (nasal type); and 2) aggressive NK-cell leukaemia. NK/T-cell lymphomas are uncommon but are more prevalent in Asia, Mexico, and Central and South America [5]. In the present case, the abdominal CT, which was taken 10 days before admission, showed no involvement of other organs except the lungs, and the physical examination on admission showed no hepatosplenomegaly. In addition, the post mortem examination did not indicate the involvement of the upper respiratory tract and the entire gastrointestinal tract. It is 

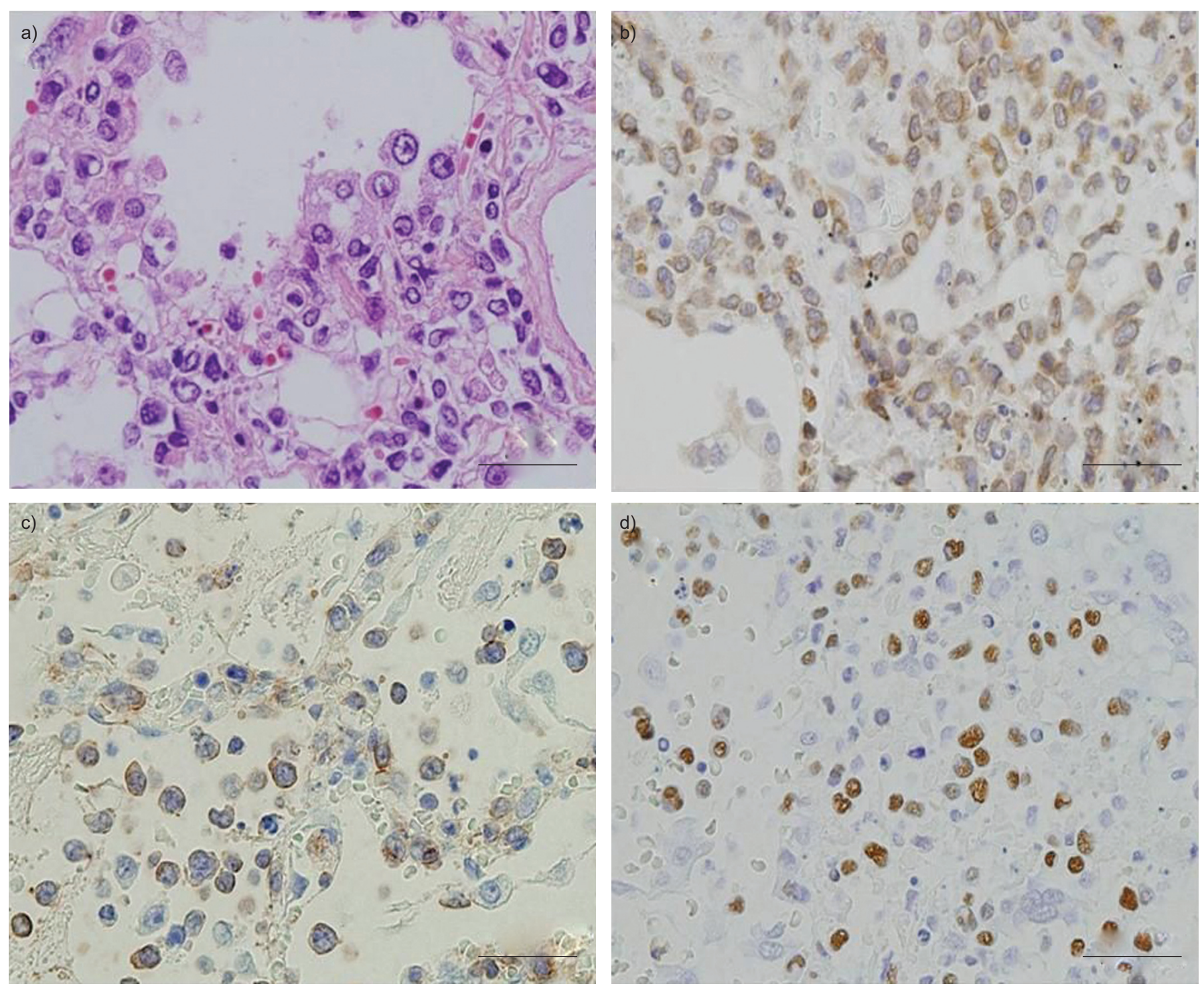

FIGURE 2. Post mortem lung histology showing proliferation of medium to large sized atypical lymphoid cells infiltrating alveolar septa. a) Haematoxylin and eosin staining. Positive staining for b) CD3, c) CD56 and d) Epstein-Barr virus-encoded small RNA was seen by immunohistochemical analysis. Scale bar $=50 \mu \mathrm{m}$.

difficult to locate the definite primary site in the present case; however, it is reasonable to suggest that the lung is the primary site, based on the clinical and radiological findings obtained before and at admission. Although lung involvement is sometimes seen in the end stage of extranodal NK/T-cell lymphoma [6-8], there have been cases of the lesions found only in the lungs even in the early stage $[3,4]$.

EBV is frequently seen in tumour cells of NK/T-cell lymphoma. The first report showing the aetiological role of EBV in the development of NK/T-cell lymphoma was published in 1990 [9]. A strong relationship between EBV infection and NK/T-cell lymphoma has been suggested. However, NK/T- and T-cell peripheral lymphomas are responsible for the majority of lymphoma-associated haemophagocytic syndrome (HPS), and it has been reported that about half of lymphoma-associated HPS is associated with EBV [10]. The patient did not fulfil the diagnostic criteria of the 2004 haemophagocytic lymphohistiocytosis guidelines on admission, but developed fever, splenomegaly, cytopenia, elevated levels of ferritin and soluble IL-2 receptor in the end stage. Although haemophagocytosis in bone marrow was not proven, we can say that the patient developed HPS during disease progression.

NK/T-cell lymphoma usually presents a highly aggressive clinical course and the prognosis is generally poor. The International Peripheral T-cell Lymphoma Project demonstrated that extranasal NK/T-cell lymphoma (nasal type) has worse clinical features and survival rate, even in cases with apparently localised disease, than nasal NK/T-cell lymphoma in extranodal NK/Tcell lymphoma [11]. The present case is considered to be at high risk at the time of admission according to the international prognostic index, from which the median overall survival for patients with stage III/IV extranasal disease is $0.28 \mathrm{yrs}$. The overall clinical course of this case was $\sim 2$ months, which is consistent with the previous report [11]. 
The standard treatment for advanced NK/T-cell lymphoma has not been determined. However, some asparaginasecontaining regimens have been reported to be effective for this disease. The results of a recent phase II study have shown L-asparaginase with methotrexate and dexamethasone to be effective for refractory or relapsing extranodal NK/T-cell lymphoma [12], and YAMAGUCHI et al. [13] have shown the efficacy of another L-asparaginase regimen containing etoposide, ifosfamide and methotrexate for NK/T-cell lymphoma.

In summary, primary pulmonary NK/T-cell lymphoma with multiple nodules in both lungs is scarcely reported. To date, only two cases of primary pulmonary NK/T-cell lymphoma have been reported in English [3, 4], and these two cases did not present multiple nodules. One presented collapse/consolidation with pleural effusion, and the other consolidation with small nodules. Our case is, therefore, the first of primary pulmonary NK/T-cell lymphoma with multiple nodules in both lung fields. Transbronchial biopsy and CT-guided core needle biopsy were not helpful for making a definite diagnosis because specimens obtained by these procedures are usually too small. As the clinical course of this disease is very rapid and aggressive, we suggest the use of surgical lung biopsy for making a definite diagnosis. Although NK/T-cell lymphoma of the lung is very uncommon, the accumulation of case-based reports sheds light on the understanding of this devastating disease.

Kengo Oshima*, Yoshinori Tanino*, Suguru Sato*, Yayoi Inokoshi*, Junpei Saito*, Takashi Ishida*, Takeaki Fukuda", Kazuo Watanabe" and Mitsuru Munakata*

*Dept of Pulmonary Medicine, Fukushima Medical University School of Medicine, and "Dept of Diagnostic Pathology, Fukushima Medical University School of Medicine, Fukushima City, Japan.

Correspondence: Y. Tanino, Dept of Pulmonary Medicine, Fukushima Medical University, 1 Hikarigaoka, Fukushima City, Fukushima 960-8157, Japan. E-mail: ytanino@fmu.ac.jp

Statement of Interest: None declared.

\section{REFERENCES}

1 Cadranel J, Wislez M, Antoine M. Primary pulmonary lymphoma. Eur Respir J 2002; 20: 750-762.

2 Chan JK, Sin VC, Wong KF, et al. Nonnasal lymphoma expressing the natural killer cell marker CD56: a clinicopathologic study of 49 cases of an uncommon aggressive neoplasm. Blood 1997; 89: 4501-4513.

3 Laohaburanakit P, Hardin KA. NK/T cell lymphoma of the lung: a case report and review of literature. Thorax 2006; 61: 267-270.

4 Lee BH, Kim SY, Kim MY, et al. CT of nasal-type T/NK cell lymphoma in the lung. J Thorac Imaging 2006; 21: 37-39.

5 Liang X, Graham DK. Natural killer cell neoplasms. Cancer 2008; 112: $1425-1436$.

6 Chang SE, Yoon GS, Huh J, et al. Comparison of primary and secondary cutaneous CD56+ NK/T cell lymphomas. Appl Immunohistochem Mol Morphol 2002; 10: 163-170.

7 Macon WR, Williams ME, Greer JP, et al. Natural killer-like T-cell lymphomas: aggressive lymphomas of T-large granular lymphocytes. Blood 1996; 87: 1474-1483.

8 Matsumoto Y, Nomura K, Kanda-Akano Y, et al. Successful treatment with Erwinia L-asparaginase for recurrent natural killer/ T cell lymphoma. Leukemia Lymphoma 2003; 44: 879-882.

9 Harabuchi Y, Yamanaka N, Kataura A, et al. Epstein-Barr virus in nasal T-cell lymphomas in patients with lethal midline granuloma. Lancet 1990; 335: 128-130.

10 Kawa K. Epstein-Barr virus-associated diseases in humans. Int $J$ Hematol 2000; 71: 108-117.

$11 \mathrm{Au}$ WY, Weisenburger DD, Intragumtornchai $\mathrm{T}$, et al. Clinical differences between nasal and extranasal natural killer/T-cell lymphoma: a study of 136 cases from the International Peripheral T-Cell Lymphoma Project. Blood 2009; 113: 3931-3937.

12 Jaccard A, Gachard N, Marin B, et al. Efficacy of L-asparaginase with methotrexate and dexamethasone (AspaMetDex regimen) in patients with refractory or relapsing extranodal NK/T-cell lymphoma, a phase 2 study. Blood 2011; 117: 1834-1839.

13 Yamaguchi M, Suzuki R, Kwong YL, et al. Phase I study of dexamethasone, methotrexate, ifosfamide, L-asparaginase, and etoposide (SMILE) chemotherapy for advanced-stage, relapsed or refractory extranodal natural killer (NK)/T-cell lymphoma and leukemia. Cancer Sci 2008; 99: 1016-1020. 